\title{
Understanding Length of Stay after Spinal Cord Injury: Insights and Limitations from the Access to Care and Timing Project
}

\author{
Anthony S. Burns, Argelio Santos, Christiana L. Cheng, Elaine Chan,2 Nader Fallah,2 Derek Atkins, \\ Marcel F. Dvorak, ${ }^{4}$ Chester Ho, Henry Ahn, Jerome Paquet, Brian K. Kwon, and Vanessa K. Noonan ${ }^{2}$
}

\begin{abstract}
Costs associated with initial hospitalization following spinal cord injury (SCI) are substantial, and a major driver of costs is the length of stay (LOS); that is, the time that the injured individual remains hospitalized prior to community reintegration. Our aim was to study the factors and variables that contribute to LOS following traumatic SCI. Modeling (process mapping of the SCI healthcare delivery system in Canada and discrete event simulation) and regression analysis using a national registry of individuals with acute traumatic SCI in Canada, existing databases, and peer-reviewed literature were used to examine the driver of LOS following traumatic SCI. In different jurisdictions, there is considerable variation in the definitions and methods used to determine LOS following SCI. System LOS can be subdivided into subcomponents, and progression through these is not unidirectional. Modeling reveals that healthcare organization and processes are important contributors to differences in LOS independent of patient demographics and injury characteristics. Future research is required to identify and improve understanding of contributors to LOS following traumatic SCI. This will help enhance system performance. Work in this area will be facilitated by the adoption of common terminology and definitions, as well as by the use of simulations and modeling.
\end{abstract}

Keywords: delivery of healthcare; health services research; LOS; SCI

\section{Introduction}

Q PINAL CORD InJURIES (SCI) are catastrophic, life-altering, costly injuries for the impacted individuals, their families, and society. Costs associated with initial hospitalization are substantial, ${ }^{1,2}$ and a major driver of costs is the length of time the injured individual remains hospitalized prior to community reintegration. This is commonly referred to as length of stay (LOS). Hospital LOS has been used to measure the performance and efficiency of healthcare systems, and to monitor patient flow through the care continuum. Achieving successful community reintegration while reducing LOS would decrease costs, resource utilization, and overall burden to the healthcare system in addition to enhancing patient flow and system efficiency. It is, therefore, of great im- portance to understand the factors and variables that contribute to LOS in different contexts and jurisdictions.

Despite the obvious importance of LOS following SCI, there has been comparatively little research on and analysis of the topic. In addition, there is substantial variability among jurisdictions for both acute care and rehabilitation (Table 1) ${ }^{3-15}$. Variations in LOS cannot be attributed entirely to injury characteristics; additional contributing factors include resource availability, the organizational characteristics of healthcare systems, financial incentives and accountabilities, and healthcare policies and administration.

To gain additional insight into the drivers of LOS, the issue was critically examined as part of the Access to Care and Timing (ACT) project. ${ }^{16-18}$ The ACT project was developed to model the healthcare delivery system in Canada for patients with traumatic SCI.

\footnotetext{
${ }^{1}$ Division of Physiatry, Department of Medicine, University of Toronto, Toronto Ontario, Canada.

${ }^{2}$ Rick Hansen Institute, Vancouver, British Columbia, Canada.

${ }^{3}$ Operations and Logistics Division, Sauder School of Business, and ${ }^{4}$ Department of Orthopaedics, University of British Columbia, Vancouver, British Columbia, Canada.

${ }^{5}$ Division of Physical Medicine \& Rehabilitation, Department of Clinical Neurosciences, University of Calgary, Calgary, Alberta, Canada.

${ }^{6}$ University of Toronto Spine Program, Toronto, Ontario, Canada.

${ }^{7}$ Université Laval, Québec, Canada.

(C) Anthony S. Burns et al., 2017; Published by Mary Ann Liebert, Inc. This Open Access article is distributed under the terms of the Creative Commons Attribution Noncommercial License (http://creativecommons.org/licenses/by-nc/4.0/) which permits any noncommercial use, distribution, and reproduction in any medium, provided the original author(s) and the source are credited.
} 
Table 1. International Reports on Length of Stay (LOS) for Traumatic Spinal Cord Injury

\begin{tabular}{|c|c|c|c|c|c|c|}
\hline Country/ Center & Year & $\begin{array}{c}\text { Sample } \\
\text { population }(\mathrm{n})\end{array}$ & $\begin{array}{c}\mathrm{LOS} \\
\text { reported as }\end{array}$ & $\begin{array}{c}\text { Acute } \\
\operatorname{LOS}(\text { days })\end{array}$ & $\begin{array}{l}\text { Rehabilitation } \\
\text { LOS (days) }\end{array}$ & $\begin{array}{l}\text { Acute and } \\
\text { rehabilitation } \\
\text { LOS (days) }\end{array}$ \\
\hline Canada $^{\mathrm{a}}$ & 2004-2015 & $\begin{array}{l}2893 \text { (acute) } \\
2101 \text { (rehab) } \\
3306 \text { (acute } \\
\text { and rehab) }\end{array}$ & $\begin{array}{l}\text { Mean (SD) } \\
\text { Median (IQR) }\end{array}$ & $\begin{array}{l}37.8(58.6) \\
23(13-44)\end{array}$ & $\begin{array}{c}99.2(77.1) \\
81(50-124)\end{array}$ & $\begin{array}{l}107.9(105.6)^{b} \\
89(28-149)^{b}\end{array}$ \\
\hline Australia/ multi-center ${ }^{3}$ & 2007-2008 & 245 & Median (IQR) & & & $138(88-212)$ \\
\hline Finland / multi-center ${ }^{4}$ & $2012-2013$ & 77 & $\begin{array}{l}\text { Mean (SD) } \\
\text { Median (range) }\end{array}$ & & & $\begin{array}{l}70.5(59.0) \\
60(2-273)\end{array}$ \\
\hline USA/ multi-center ${ }^{5}$ & 2010-2015 & $\begin{array}{l}1158 \text { (acute) } \\
1180 \text { (rehab) }\end{array}$ & Median & 11 & 36 & \\
\hline China/ multi-center ${ }^{6}$ & $2007-2010$ & 761 & Median (range) & $17(1-80)$ & & \\
\hline Netherlands/ multi-center ${ }^{7}$ & 2010 & 185 & Mean $(95 \% \mathrm{CI})$ & $25(20.7-28.7)$ & & \\
\hline $\begin{array}{l}\text { South Africa/ } \\
\quad \text { Single center }\end{array}$ & 2003-2014 & 2042 & Mean & 28 & & \\
\hline India/ single center ${ }^{9}$ & 2009-2010 & 47 & Mean (SD) & & $93.34(40.95)$ & \\
\hline $\begin{array}{l}\text { Netherlands and } \\
\text { Belgium/ multi-center }\end{array}$ & $2002-2007$ & 339 & $\begin{array}{l}\text { Mean (SD) } \\
\text { Median (IQR) }\end{array}$ & & $\begin{array}{c}227.6(105.2) \\
207.0(116.0-307.0)\end{array}$ & \\
\hline Saudi Arabia/ single center ${ }^{11}$ & 2005-2008 & 495 & Mean (SD) & & $58.8(4.68)$ & \\
\hline Serbia/ single center ${ }^{12}$ & $2000-2009$ & 279 & Mean (SD) Range & & $\begin{array}{c}169(85.72) \\
16-380\end{array}$ & \\
\hline South Korea/ single center ${ }^{13}$ & 2004-2008 & 481 & Mean (SD) & & $55(39)$ & \\
\hline Thailand/ single center ${ }^{14}$ & 2006-2010 & 85 & $\begin{array}{l}\text { Mean (SD) } \\
\text { Median (range) }\end{array}$ & & $\begin{array}{l}37.8(25.8) \\
41.3(21.7)\end{array}$ & \\
\hline Turkey/ single center ${ }^{15}$ & 2000-2007 & 905 & Mean (SD) Range & & $\begin{array}{l}73.6(49.8) \\
3-424\end{array}$ & \\
\hline
\end{tabular}

${ }^{a}$ Data for Canada derived from the Rick Hansen Spinal Cord Injury Registry.

${ }^{\mathrm{b}}$ Total LOS could be simply acute LOS if they were discharged directly from an acute facility.

IQR, interquartile range; CI confidence interval.

Techniques from operations research, such as simulation modeling, were used to predict the impact of best practices and policy initiatives on outcomes related to both the system and patients. Similar methodologies have been used extensively in business and engineering to evaluate best practices and optimize complex processes. It is anticipated that findings from simulated scenarios can be used to inform decisions on optimizing practice across the care continuum.

\section{Methods}

The development of the ACT simulation model for traumatic SCI care has been previously described. ${ }^{16-18}$ The ACT project was implemented in Canadian facilities participating in a prospective longitudinal traumatic SCI patient registry, referred to as the Rick Hansen SCI Registry (RHSCIR). Participating sites in the RHSCIR include include high volume acute trauma facilities and specialized rehabilitation facilities in Canada. ${ }^{19}$ RHSCIR data used in the ACT model relate to patient and injury characteristics, timing to care, and outcomes (e.g., LOS, mortality, discharge American Spinal Injury Association Impairment Scale [AIS] grade). The full list of data variables has been previously published. ${ }^{18}$

ACT methodology incorporated process mapping to document patient flow and resources at participating facilities and to provide the basis for the computer simulation of the ACT model. For a detailed description of process mapping, readers can reference Noonan and coworkers. ${ }^{16}$ The purpose of the Level 1 process maps was threefold: 1) to document patient flow and basic processes of SCI care starting from the point of injury through to community reintegration, 2) to identify and capture important differences in the delivery of care among facilities, and 3) to identify facilities for detailed simulation.

Discrete event simulation (DES) modeling was used to further characterize the pre-hospital, acute, and rehabilitation phases of care. The DES methodology was described in detail by Noonan and coworkers. ${ }^{16}$ DES requires detailed input data. The RHSCIR was the most appropriate data source for developing the simulation model, as it captures data elements from healthcare facilities across Canada from the time of injury through to 1,2 , and every 5 years post-injury until death or a participant's voluntary withdrawal from the study. Data from RHSCIR were supplemented by additional hospital and national databases, including the Canadian Institute for Health Information National Rehabilitation Reporting System. In instances in which data were not available, literature searches were conducted and relevant information was obtained from subject matter experts. Examples of data derived from the published literature include incidence of secondary complications; dependence of LOS on injury type, complications, and comorbidities; and economic data such as direct healthcare costs. The current ACT model simulates nine acute facilities and seven rehabilitation facilities in Canada.

\section{Defining LOS}

Variability in the reporting and capture of LOS was explored using two approaches: 1) a search of representative Canadian and international databases and data sets was conducted to document existing variability in the definitions of LOS; and 2) a literature review of international reports of LOS was conducted to obtain a global snapshot of variability of LOS. PubMed was searched using the search terms spinal cord injury AND (length of stay OR duration of care OR hospital days OR epidemiology), for the period 2006-2016.

\section{LOS Modeling}

To model and predict LOS for different participating jurisdictions, regression analysis was performed using simulation inputs. In the context of this modeling activity, jurisdiction refers to both an 
acute and a rehabilitation facility. Inputs included age, gender, direct admission to specialized center, time from injury to admission to a specialized center, death in acute care, mechanism of injury, neurological level of injury, AIS grade, and a jurisdiction adjusting factor. The jurisdiction adjusting factor incorporated clinical protocols, therapeutic decision making, and resource capabilities, the details of which were reported by Noonan and coworkers. ${ }^{16}$ The simulation generated and accommodated theoretical cohorts of patients with differing demographics or injury characteristics, and predicted mean LOS for participating jurisdictions.

Because the calculation of LOS for jurisdictions includes predictors related to 1) patient demographics, 2) injury characteristics, and 3) a jurisdiction adjusting factor, the impact of changing patient demographics and/or injury characteristics can be determined by leaving the jurisdiction adjusting factor unchanged. When LOS does not change significantly after switching patient demographics and/or injury characteristics, it is assumed that the LOS is driven primarily by the jurisdiction specific adjusting factor.

Jurisdictional differences in processes of care may be captured in part by calculating LOS using different definitions. For example, acute LOS can be calculated for one particular acute facility, or alternatively as the accumulated LOS for all acute facilities visited during the acute phase of care. This is important because some patients are treated at only one acute facility following injury, whereas others are treated at multiple acute facilities. To illustrate the impact of definitions, mean and median acute LOS were calculated, using a cohort of patients from two participating RHSCIR acute facilities prior to 2012, using different parameters: 1) the interval between date of admission and date of discharge from the designated (RHSCIR) acute facility, and 2) the interval between date of admission to any acute facility to date of final discharge from any acute facility. The cohort included participants admitted to the RHSCIR acute facility. Only participants who also went to rehabilitation were included in the cohort to reduce variation. LOS was calculated with outliers (defined using the $1.5 \times$ interquartile range rule) removed, and the sign test was used to test for significant differences between parameters 1 and 2 for each facility.

\section{Results}

\section{Modeling of LOS in Canada}

Based on jurisdiction-specific characteristics and processes, a model was constructed for two existing healthcare systems in the Canadian context. Site-specific outcomes were then determined when the model was applied to theoretical cohorts of patients from six distinct jurisdictions. Results of modeling revealed that independent of the patient cohort (demographics and injury characteristics), there were persistent and significant discrepancies between the two modeled sites with regard to time to surgery $(<24 \mathrm{~h})$, mean acute LOS (days), mean rehabilitation LOS (days), mean total LOS (days), mean LOS care costs in Canadian dollars (CDN), and mean rest of life costs (CDN) (Table 2). These differences can be attributed to jurisdiction- specific differences in the "processes" of care. Using cohort 1 as example, projected mean total LOS was 141 days in jurisdiction 1 versus 114 days in jurisdiction 2. Similarly, when cohort 2 was modeled, the discrepancy in mean total LOS persisted, with a mean LOS of 139 days in jurisdiction 1 versus 113 days in jurisdiction 2. The pattern remained consistent for all six patient cohorts, with jurisdiction 1 demonstrating a longer time to surgery, longer mean LOS (acute, rehabilitation, total), and higher associated healthcare costs.

In addition to the impact of jurisdiction-specific processes on LOS, additional analysis demonstrated that differences in definitions can also contribute to significant discrepancies in calculated LOS (Table 3). Acute LOS can be reported as the number of days in a specific acute facility, or alternatively as the interval incorporating admission to any acute facility to discharge from any acute facility (potentially multiple acute facilities). Using alternative definitions of LOS leads to significant differences $(p<0.001)$ in observed LOS when applied to two distinct, modeled acute care facilities.

\section{Discussion}

The ACT project revealed that 1) LOS is neither a singular nor an obvious concept, and that there is substantial variability in how it is defined and determined, and 2) organizational structure and processes specific to a jurisdiction (healthcare system) can impact LOS independent of patient demographics and injury characteristics.

\section{Definitions and determinants of LOS}

LOS is a reflection of the entire care continuum and, as such, can be subdivided into the individual components that comprise the care continuum (Fig. 1). Development of the ACT simulation

Table 2. Impact of Jurisdiction on Projected Length of Stay (LOS) and Cost

\begin{tabular}{lccccccc}
\hline $\begin{array}{l}\text { Patients from } \\
\text { jurisdiction }\end{array}$ & Jurisdiction & $\begin{array}{c}\text { Surgery } \\
<24 h(\%)\end{array}$ & $\begin{array}{c}\text { Acute LOS } \\
\text { (mean, days) }\end{array}$ & $\begin{array}{c}\text { Rehab LOS } \\
\text { (mean, days) }\end{array}$ & $\begin{array}{c}\text { Total LOS } \\
\text { (mean, days) }\end{array}$ & $\begin{array}{c}\text { LOS care cost } \\
\text { (mean, CDN\$) }\end{array}$ & $\begin{array}{c}\text { Rest of life cost } \\
(\text { mean, CDN\$) }\end{array}$ \\
\hline 1 & 1 & $36.0 \%$ & 39.7 & 101.4 & 141.13 & $103,255.85$ \\
& 2 & $20.6 \%$ & 33.7 & 80.1 & 113.8 & $86,811.42$ & $677,111.27$ \\
2 & 1 & $41.8 \%$ & 39.1 & 100.2 & 139.29 & $98,963.70$ & $683,078.36$ \\
& 2 & $26.1 \%$ & 34.0 & 79.3 & 113.3 & $89,430.44$ & $762,294.78$ \\
3 & 1 & $41.7 \%$ & 39.5 & 100.7 & 140.26 & $103,175.58$ & $791,069.93$ \\
& 2 & $26.0 \%$ & 33.7 & 80.0 & 113.7 & $89,396.06$ & $779,735.08$ \\
4 & 1 & $40.8 \%$ & 37.2 & 95.6 & 132.76 & $94,667.35$ & $764,654.80$ \\
& 2 & $23.5 \%$ & 32.4 & 75.7 & 108.1 & $83,594.90$ & $758,316.10$ \\
5 & 1 & $43.0 \%$ & 39.4 & 100.9 & 140.30 & $102,383.88$ & $774,426.02$ \\
& 2 & $27.0 \%$ & 33.1 & 80.0 & 113.1 & $88,453.54$ & $764,251.86$ \\
6 & 1 & $36.6 \%$ & 39.4 & 102.9 & 142.32 & $100,457.60$ & $627,483.37$ \\
& 2 & $22.3 \%$ & 34.0 & 80.1 & 114.2 & $86,392.67$ & $626,547.87$ \\
\hline
\end{tabular}

Jurisdiction refers to both an acute and rehabilitation facility. 
Table 3. Impact of Definition on Calculated Acute Length of Stay

\begin{tabular}{|c|c|c|c|c|c|}
\hline Facility & $\mathrm{n}$ & & $\begin{array}{l}\text { Interval between date of } \\
\text { admission to RHSCIR acute } \\
\text { facility and date of discharge } \\
\text { from RHSCIR acute facility }\end{array}$ & $\begin{array}{l}\text { Interval between date of } \\
\text { admission to any acute facility } \\
\text { and date of final discharge } \\
\text { from any acute facility }\end{array}$ & $\mathrm{p}$ value \\
\hline \multirow[t]{2}{*}{1} & 368 & Mean $(95 \%$ CI) & $38.6(36.3-40.9)$ & $40.2(37.9-42.6)$ & \\
\hline & 369 & Median (IQR) & $33.5(29.5)$ & $35(31)$ & $<0.0001$ \\
\hline \multirow[t]{2}{*}{2} & 139 & Mean $(95 \%$ CI $)$ & $23.6(20.9-26.3)$ & $30(26.3-33.7)$ & \\
\hline & 140 & Median (IQR) & $19(20)$ & $23(25.5)$ & $<0.0001$ \\
\hline
\end{tabular}

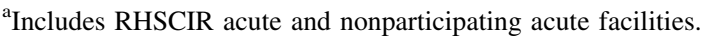

RHSCIR, Rick Hansen Spinal Cord Injury Registry; CI, confidence interval; IQR, interquartile range.

model for traumatic SCI revealed that the definition, determination, and reporting of LOS varies considerably (Tables 1 and 4). System LOS can be used to describe the interval from time of injury to community reintegration. In turn, system LOS can be divided into acute LOS and rehabilitation LOS. An individual's progression through the continuum of care is not always seamless or ideal, and the interval prior to rehabilitation can involve more than one acute facility. As a result, LOS can also be designated for individual facilities. Admission to and discharge from rehabilitation can be influenced by barriers to discharge. As a result, individuals can remain in the rehabilitation setting after rehabilitation goals have been met and the individual is deemed ready for discharge. Finally, progression through the continuum of care is not unidirectional, and readmissions to alternative care settings are often required (e.g., service interruption resulting in rehabilitation to acute care transfer). The differing definitions and perspectives with regard to LOS are reflected in the number of data elements related to LOS that are collected by RHSCIR (Table 5), and the varying definitions of LOS that can be calculated (Table 4).

The nature and accuracy of data related to LOS are dependent upon how it is defined. Caution, therefore, must be taken when using LOS to compare the processes and outcomes of healthcare systems. As an example, one might be interested in the acute LOS or time prior to the initiation of rehabilitation. It might be tempting to determine facility LOS for the acute hospital and/or trauma center where the predominance of care was provided. Data of this nature are often readily available from hospital records or databases. However although this may be convenient, as illustrated in Figure 1 and Table 3, this construct does not necessarily capture the entirety of the pre-rehabilitation care interval, particularly if care was rendered at more than one acute hospital or an alternative level of care (e.g., convalescence) was required prior to the initiation of active rehabilitation. As a consequence, future studies need to employ more rigor when investigating and analyzing the determinants of LOS. An advantage of RHSCIR as a data source is that LOS can be calculated using varying definitions (Table 5).

Different audiences are also likely to be interested in different aspects of LOS. A hospital administrator might monitor institutional performance using LOS for a specific facility. In comparison, a regional healthcare authority and funder will be interested in the performance of a health system as a whole. System LOS, representing the entirety of care prior to community reintegration, would need to capture all aspects of the care continuum. Currently, the calculation of system LOS is often hampered by the fact that relevant data are often defined differently and distributed across multiple facilities and/or databases.

\section{Need and advantages of standardization}

It is apparent from study findings that there is a need to develop and encourage the use of standardized definitions for the individual components of LOS following SCI. Proposed terminology and definitions are presented in Table 6 . A consensus process to support the validity of the proposed terminology is needed, as the potential benefits to the field and future research are many. The use of LOS as an indicator of patient flow and system efficiency would require it to be defined, collected, and measured consistently across institutions and jurisdictions. Common terminology would facilitate comparisons between institutions and jurisdictions. Contributors to LOS variance could then be scrutinized and analyzed in greater detail. Common terminology would also facilitate the collection of consistent and valid data; data that in turn would facilitate benchmarking. Benchmarking is integral to effective goal-setting and performance enhancement. ${ }^{20}$ Finally, common terminology would

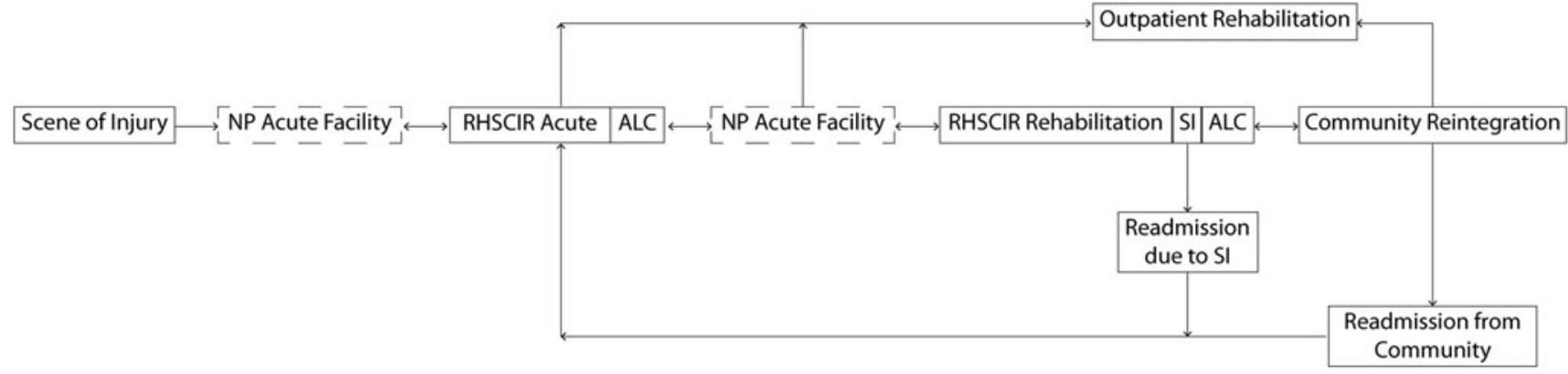

FIG. 1. Continuum of care following spinal cord injury. NP, nonparticipating; RHSCIR, Rick Hansen Spinal Cord Injury Registry; ALC, alternate level of care; SI, service interruption. 
Table 4. Definitions of Acute and Rehabilitation Length of Stay (LOS)

Source

Acute

Term

Definition

Accreditation Canada

(Trauma Distinction)

National Trauma Registry

Discharge Abstract

Database

National SCI

Statistical Center
Acute LOS

Acute LOS

Acute LOS

Acute LOS

Acute LOS

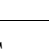

$\sqrt{2}+x^{2}$


Table 6. Common Terminology for Length of Stay (LOS)

\begin{tabular}{ll} 
Term & \multicolumn{1}{c}{ Definition } \\
\hline System length of stay & $\begin{array}{c}\text { The interval (days) extending from initial injury to community reintegration or discharge to } \\
\text { long-term residential care } \\
\text { The interval (days) from initial injury to rehabilitation admission } \\
\text { The interval (days) from rehabilitation admission to community reintegration or discharge to } \\
\text { long-term residential care } \\
\text { The interval (days) extending from admission to facility to discharge. The term can be applied } \\
\text { Rehabilitation length of stay } \\
\text { to acute care or rehabilitation. }\end{array}$ \\
$\begin{array}{l}\text { Facility length of stay } \\
\text { The interval (days) when an individual has been deemed to no longer require a specific level of } \\
\text { care but remains admitted secondary to discharge barriers. The term can be applied to acute } \\
\text { care or rehabilitation. }\end{array}$ \\
$\begin{array}{l}\text { The interval (days) during rehabilitation LOS when an individual temporarily is unable to } \\
\text { participate in rehabilitation because of medical instability and/or requirements for evaluation/ }\end{array}$ \\
$\begin{array}{l}\text { treatment in an acute care facility } \\
\text { The acute LOS minus the alternative level of care designation interval } \\
\text { Duration of acute care } \\
\text { The rehabilitation LOS minus service interruption(s) minus alternative level of care designation } \\
\text { rehabilitation }\end{array}$
\end{tabular}

In the simulation exercise described, it was demonstrated that LOS continued to vary between two jurisdictions even after theoretical patient cohorts were switched between the jurisdictions. Modeling facilitates the identification of contributors to LOS that might not be immediately apparent, and whose impact might ripple through the entire continuum of care. To illustrate this point, the increased availability of accessible community housing could theoretically decrease rehabilitation facility LOS, and in turn increase the availability of rehabilitation beds. Increased rehabilitation beds in turn could expedite transfers from acute care and reduce acute facility LOS.

The role of computer simulations and modeling in assessing the impact of models of care on patient flow and LOS is in its infancy and its application has been limited. ${ }^{26}$ An advantage of modeling is that it provides a preliminary assessment of the impact of an intervention prior to proceeding to full implementation. The importance of this cannot be understated given the costs, resources, and human capital associated with implementing substantive change. As an example, the impact of increased accessible housing in the community on system performance could be modeled prior to the commitment of tangible resources.

\section{Limitations}

It should be acknowledged that there are limitations associated with modeling. Given its nature, no model will precisely represent clinical reality, and results are dependent upon the inputs and accompanying assumptions. In particular, modeling requires the availability of accurate data to populate the model. Despite these limitations, rigorous and systematic modeling can provide reasonable approximations, which in turn can inform decision making.

\section{Conclusion}

LOS is one of the primary drivers of hospital costs following traumatic SCI, and, as such, is an important measure of healthcare system performance and efficiency. Independent of patient demographics and injury characteristics, factors such as the organization of healthcare systems and accompanying processes contribute significantly to observed LOS. Identification of contributors will facilitate performance improvement within healthcare systems. Despite this importance, there is a relative dearth of research ad- dressing the determinants of LOS. Efforts are further hampered by variability in defining and determining LOS, as well as the lack of a common terminology. Future research addressing LOS after traumatic SCI will be enhanced by the adoption of common terminology and definitions, as well as the use of simulations and modeling.

\section{Acknowledgments}

The authors thank Dilinuer Kuerban for statistical support, the Rick Hansen Institute RHSCIR Team (Suzanne Humphreys, Daniel Rogers, Kristen Walden, Jayson Shurgold, Jessica Eapen, Jerome Buenaventura, Tova Plashkes, Arlene Aspinall, Cynthia Morin, and Shannon Sproule); and the RHSCIR Network and the facilities who participated in this study. This study was supported by financial contributions from the Rick Hansen Institute and the Government of Canada through Health Canada and Western Economic Diversification Canada.

\section{Author Disclosure Statement}

No competing financial interests exist.

\section{References}

1. Cao, Y., Chen, Y., and DeVivo, M. (2011). Lifetime direct costs after spinal cord injury. Top. Spinal Cord Inj. Rehabil. 16, 10-16.

2. DeVivo, M., Chen, Y., Mennemeyer, S., and Deutsch, A. (2011). Costs of care following spinal cord injury. Top. Spinal Cord Inj. Rehabil. 16, 1-9.

3. Norton, L. (2010). Spinal cord injury, Australia 2007-2008 (full publication) Australian Institute of Health and Welfare, Canberra, Australia.

4. Koskinen, E.A., Alen, M., Väärälä, E.M., Rellman, J., Kallinen, M., and Vainionpää, A. (2014). Centralized spinal cord injury care in Finland: unveiling the hidden incidence of traumatic injuries. Spinal Cord 52, 779-784.

5. National Spinal Cord Injury Statistical Centre (2014). 2014 Annual Report Complete Public Version. National Spinal Cord Injury Statistical Center, University of Alabama at Birmingham, Birmingham, Alabama.

6. Wang, H.F., Yin, Z.S., Chen, Y., Duan, Z.H., Hou, S., and He, J. (2013). Epidemiological features of traumatic spinal cord injury in Anhui Province, China. Spinal Cord 51, 20-22.

7. Nijendijk, J.H., Post, M.W., and van Asbeck, F.W. (2014). Epidemiology of traumatic spinal cord injuries in the Netherlands in 2010. Spinal Cord 52, 258-263. 
8. Sothmann, J., Stander, J., Kruger, N., and R, D. (2015). Epidemiology of acute spinal cord injuries in the Groote Schuur Hospital Acute Spinal Cord Injury (GSH ASCI) Unit, Cape Town, South Africa, over the past 11 years. S. Afr. Med. J. 105, 835-9.

9. Equebal, A, Anwer, S., and Kumar, R. (2013). The prevalence and impact of age and gender on rehabilitation outcomes in spinal cord injury in India: a retrospective pilot study. Spinal Cord 51, 409-412.

10. Osterthun, R., Post, M.W., and van Asbeck, F.W. (2009). Characteristics, length of stay and functional outcome of patients with spinal cord injury in Dutch and Flemish rehabilitation centres. Spinal Cord 47, 339-344.

11. Al-Jadid, M., and Robert, A. (2010). Al Jadid 2010. Saudi Med. J. 31, 555-559.

12. Milicevic, S., Bukumiric, Z., Karadzov-Nikolic, A., Babovic, R., and Jankovic, S. (2012). Demographic characteristics and functional outcomes in patients with traumatic and nontraumatic spinal cord injuries. Vojnosanit. Pregl. 69, 1061-1066.

13. Shin, J.C., Kim, D.H., Yu, S.J., Yang, H.E., and Yoon, S.Y. (2013). Epidemiologic change of patients with spinal cord injury. Ann. Rehabil. Med. 37, 50-56.

14. Rinkaewkan, P., and Kuptniratsaikul, V. (2015). The effectiveness of inpatients rehabilitation for spinal cord patients in Siriraj hospital. Spinal Cord 53, 591-597.

15. Tuğcu, İ., Tok, F., Yilmaz, B., Göktepe, A.S., Alaca, R., Yazicioğlu, K., and Möhür, H. (2011). Epidemiologic data of the patients with spinal cord injury: Seven years' experience of a single center. Ulus Travma Acil Cerrahi Derg. 17, 533-538.

16. Noonan, V.K., Soril, L., Atkins, D., Lewis, R., Santos, A., Fehlings, M.G., Burns, A.S., Singh, A., and Dvorak, M.F. (2012). The application of operations research methodologies to the delivery of care model for traumatic spinal cord injury: the access to care and timing project. J. Neurotrauma 29, 2272-2282.

17. Atkins, D., Noonan, V.K., Santos, A., Lewis, R., Fehlings, M., Burns, A., and Dvorak, M. (2012). Secondary complications in SCI across the continuum: Using operations research to predict the impact and optimize management strategies. Top. Spinal Cord Inj. Rehabil. 18, 57-66.

18. Santos, A., Gurling, J., Dvorak, M.F., Noonan, V.K., Fehlings, M.G., Burns, A.S., Lewis, R., Soril, L., Fallah, N., Street, J.T., Bélanger, L. Townson, A., Liang, L., and Atkins, D. (2013). Modeling the patient journey from injury to community reintegration for persons with acute traumatic spinal cord injury in a Canadian centre. PLoS One 8 , e72552.
19. Noonan, V., Kwon, B., Soril, L., Fehlings, M., Hurlbert, R., Townson, A., Johnson, M., and Dvorak, M. (2012). The Rick Hansen Spinal Cord Injury Registry (RHSCIR): A national patient-registry. Spinal Cord 50, 22-27.

20. Burns, A.S., Yee, J., Flett, H.M., Guy, K., and Cournoyea, N. (2013) Impact of benchmarking and clinical decision making tools on rehabilitation length of stay following spinal cord injury. Spinal Cord 51, 165-169.

21. Bradley, L.J., Kirker, S.G.B., Corteen, E., Seeley, H.M., Pickard, J.D. and Hutchinson, P.J. (2006). Inappropriate acute neurosurgical bed occupancy and short falls in rehabilitation: implications for the $\mathrm{Na}$ tional Service Framework. Br. J. Neurosurg. 20, 36-39.

22. New, P.W. (2014). Reducing process barriers in acute hospital for spinal cord damage patients needing spinal rehabilitation unit admission. Spinal Cord 52, 472-476.

23. New, P.W., Scivoletto, G., Smith, É., Townson, A., Gupta, A., Reeves, R.K., Post, M.W., Eriks-Hoogland, I., Gill, Z.A., and Belci, M. (2013) International survey of perceived barriers to admission and discharge from spinal cord injury rehabilitation units. Spinal Cord 51, 893-897.

24. New, P.W. (2015). Prospective study of barriers to discharge from a spinal cord injury rehabilitation unit. Spinal Cord 53, 358-362.

25. New, P.W., Townson, A., Scivoletto, G., Post, M.W., Eriks-Hoogland, I., Gupta, A., Smith, É., Reeves, R.K., and Gill, Z.A. (2013). International comparison of the organisation of rehabilitation services and systems of care for patients with spinal cord injury. Spinal Cord 51, 33-9.

26. New, P.W., Stockman, K., Cameron, P.A., Olver, J.H., and Stoelwinder, J.U. (2015). Computer simulation of improvements in hospital length of stay for rehabilitation patients. J. Rehabil. Med. 47, 403-411.

Address correspondence to: Anthony S. Burns, MD, MSc

Division of Physiatry

Department of Medicine University of Toronto 520 Sutherland Drive

Toronto, Ontario M4G 3V9 Canada

E-mail: Anthony.Burns@uhn.ca 